\title{
El fragmento y la detención. Literatura y cine en Juan José Saer
}

\author{
David Oubiña*
}

\begin{abstract}
Resumen
¿Cuál es la relación que la literatura moderna establece con el cine? ¿En qué tipo de películas piensan los escritores? ¿Qué cosas toman los textos de los films? Fuertemente marcada por las innovaciones en el estatuto de la narración, la obra de Juan José Saer no ha escapado al influjo magnético de lo cinematográfico. Pero aunque utiliza técnicas de los films para poner en cuestión el relato literario clásico, nunca adopta el modelo del cine dominante; más bien, al contrario, aprovecha los recursos de fragmentación y detención que se encuentran en la base de las películas para construir una nueva forma de especificidad literaria. Pero si Saer utiliza al cine en su negatividad, ¿cómo trabajar, entonces, estos relatos desde las películas? ¿Cómo transformar las palabras en imágenes sin avenirse a una mera ilustración que elimine todas las fricciones, que suavice todos los contrastes? Este ensayo pone en relación la serie literaria y la cinematográfica para reflexionar sobre los modos en que la obra de Saer ha hecho uso de los dispositivos fílmicos y los modos en que las películas han adaptado sus novelas.
\end{abstract}

\section{Palabras clave}

Literatura moderna. Adaptación cinematográfica. Dispositivos cinematográficos. Cronofotografía. Fragmentación y detención del movimiento.

\section{El cine en la literatura}

La obra de Juan José Saer puede reclamar, de pleno derecho, su pertenencia a la gran tradición de la literatura moderna. Si por un lado reconoce su genealogía en la narración decimonónica, por otro lado es consciente de la distancia insalvable que las separa. Dice el escritor: "Proust, Joyce, Kafka, Musil son los que realmente transformaron la noción misma de narración. La novela clásica del siglo XIX desaparece por completo con ellos. Enraizados como estaban en esa tradición, se inscribieron en ella de la mejor manera posible: modificándola" (Saavedra, 1993, p. 178). En ese singular sistema de relevos que parece organizar la historia del arte, la narración decimonónica -abandonada por la literatura- pasó al cine. A comienzos de

* Universidad de Buenos Aires - CONICET. 
siglo, cuando David Griffith era criticado por introducir en sus films procedimientos novelescos a través del montaje, su defensa era: "¿Acaso Dickens no escribe así? La diferencia no es tan grande: yo hago novelas en imágenes" (Company, 1987, p. 19). ${ }^{1}$ Pero también es cierto que las nuevas técnicas del cine pronto invadieron el territorio de las artes tradicionales -empezando por la propia literatura moderna- para establecer una zona de contaminación e intercambio: Sergei Eisenstein llamó a Ulises "la Biblia del nuevo cine", fascinado con las posibilidades de hallar una técnica cinematográfica que lograse traducir el recurso literario del flujo de conciencia, mientras Joyce comentaba que Walter Ruttman era el candidato ideal para llevar su novela a la pantalla. La escena del escritor negociando con el nuevo invento sus técnicas novelísticas hace evidente que, en algún momento, de alguna u otra manera, toda la gran literatura del siglo XX ha lindado con el cinematógrafo. ${ }^{2}$

¿Cuál es la relación que la literatura moderna establece con el cine? ¿En qué tipo de películas piensan los escritores? ¿Qué cosas toman los textos de los films? Fuertemente marcada por las innovaciones en el estatuto de la narración, la obra de Saer no ha escapado al influjo magnético de lo cinematográfico. La importancia del cine en su formación literaria y en la composición de sus novelas ha sido destacada tanto por los críticos como por el propio autor. Graciela Montaldo, por ejemplo, señala que la estructura de El limonero real evoca la organización narrativa de Hace un año en Marienbad (Alain Resnais, 1961) y Raúl Beceyro analiza El río sin orillas como si fuera un film documental. ${ }^{3} \mathrm{Y}$ así como Saer nunca deja de enumerar su árbol genealógico de escritores (Joyce, Kafka, Faulkner, Proust, Flaubert, Musil, Borges, Di Benedetto, Arlt, Macedonio Fernández, Juan L. Ortiz), también cita con la misma perseverancia su tradición cinematográfica: Ingmar Bergman, Michelangelo Antonioni, Andrei Tarkovski, Yazujiro Ozu, Satyajit Ray, Robert Bresson, John Casavettes, Rainer Fassbinder y Jean-Luc Godard.

En sus inicios, Saer fue profesor de Historia del cine y de Crítica y estética cinematográfica en la Universidad Nacional del Litoral. También ha sido guionista de El encuentro (Dino Minitti, 1966), de Palo y hueso (Nicolás Sarquís, 1967) y de Las veredas de Saturno (Hugo Santiago, 1985) entre otros films. Esa estrecha convivencia con cierto imaginario cinematográfico dejó marcas permanentes en su escritura: el carácter organizador de la mirada, los cambios de perspectiva, la construcción del espacio, el slow motion, el desmontaje de las acciones, el manejo del flashback, el fuera de campo o el aprovechamiento de los tiempos muertos son técnicas que el escritor aprende del cine y que le sirven para cuestionar la linealidad narrativa y la

${ }^{1}$ Eso es, por otra parte, lo que sostiene Ricardo Piglia: "Esa máquina de hacer ficción que es el cine depende del relato tradicional. La novela del siglo diecinueve está hoy en el cine. El que quiere narrar como narraba Balzac o Zola, que haga cine" (Piglia, 1990, p. 42).

2 En 1909, Joyce (que aún no era Joyce: sólo tenía en su haber el libro de poemas Música de cámara, 1907) abrió en Dublín el Cinematograph Volta, la primera sala de cine de Irlanda. Aunque es una mera referencia anecdótica, no deja de ser significativa ya que ilustra la auténtica fascinación que los artistas experimentaron ante la aparición de las imágenes en movimiento.

${ }^{3}$ Véase Montaldo, 1986, p. 58 y Beceyro, 1992, p. 28. Por su parte, Saer se refiere a los efectos de cierto cine moderno en la arquitectura de sus relatos: "En mi primera novela, La vuelta completa, hay elementos probablemente sacados de algunos films de Antonioni" (Oubiña y Ricagno, 1994, p. 24). 
estética realista. Saer usa técnicas del cine para separarse del relato literario clásico y, en ese movimiento, construye una nueva forma de especificidad literaria. Ya no se trata del esquema lineal y progresivo del realismo clásico sino una escritura rumiada que se dilata, se expande, se interrumpe y avanza de una manera errática o zigzagueante. Más que referir hechos que han ocurrido, los textos del escritor parecerían aferrarse a una descripción instantánea de los acontecimientos. Describir lo que ocurre en el momento mismo en que ocurre. Como si lo fotografiara. Beatriz Sarlo escribe a propósito de Nadie nada nunca: "Lo que en la novela se cuenta, más que un conjunto de peripecias o la historia de una subjetividad negada, son los estados del presente, que deja de ser lineal para adquirir el espesor que le proporcionan los leves desplazamientos de perspectiva. El espesor resulta, también, de las formas en que se escribe, de manera cada vez más expandida, el mismo estado del presente" (Sarlo, 1980 , p. 34). ${ }^{4}$ El trabajo sobre ese estado del presente, cuyas mutaciones intentan ser registradas minuciosamente por la escritura, revela la influencia de cierta literatura y cierto cine modernos.

¿Pero, concretamente, qué toma Saer del cine en el nivel de los procedimientos? Se podría responder: la fragmentación y la detención. He ahí las técnicas que definen el mecanismo del registro cinematográfico. Para lograr una proyección fluida del movimiento y del tiempo, el cine debe capturar las acciones parcelándolas y congelándolas. De allí resulta que el registro y la proyección son momentos opuestos y complementarios. (Significativamente el aparato ideado por los Lumière contenía en sí mismo esa contradicción: era cámara y proyector a la vez.) Digamos que, para proyectar la continuidad, es preciso pasar por lo discontinuo. En La mayor, en El limonero real o en Nadie nada nunca, por ejemplo, la percepción funciona por fragmentación: para procesar la gran masa de informaciones que recogen los sentidos, es preciso segmentar el entorno, aislar allí un momento, descomponerlo y examinar sus partes analíticamente. Aunque, al hacerlo, inevitablemente produce una sensación del objeto en la que éste no podría reconocerse. Para describir la acción aparentemente simple de engullir un bocado o subir una escalera o manejar un automóvil bajo la lluvia o caminar por la orilla del río, es preciso atravesar un laberinto de pequeños actos autónomos que terminan por diluir al objeto entre los pliegues de su propia descripción.

Sin duda, Glosa es la gran novela sobre la detención: la acción completa del texto, cabe en el espacio acotado de las 21 cuadras que recorren juntos Angel Leto y el Matemático. Allí se extrema el procedimiento para extraer el máximo de información en cada instante de la caminata. Saer no trabaja sobre el movimiento para aprovechar su intrínseca fluidez sino, curiosamente, para desmontar un paradigma de representación basado en la linealidad y lo continuo. Si los procedimientos cinematográficos ocupan un sitio original en su escritura, es porque hace un uso subversivo del medio. No sólo aprovecha el cine como instrumento para interrogar

${ }^{4}$ A menudo $-y$ a pesar de la insistencia con que Saer intentó desmentirlo- se ha mencionado la influencia del Nouveau Roman. Véase, por ejemplo, la importancia que Robbe-Grillet asigna a la descripción en ciertas formas (literarias y cinematográficas) del relato moderno: la descripción como un dispositivo de detención o de interrupción, obsesionada por la captura de los instantes que, inevitablemente, niegan la continuidad (Robbe-Grillet, 1964). 
ciertas convenciones o procedimientos literarios cristalizados sino que, en ese movimiento, el propio dispositivo cinematográfico es puesto en cuestión. Se trata de una doble violencia que lo vuelve irrecuperable para las prácticas institucionalizadas tanto del cine como de la literatura. En lugar de descansar sobre la construida fluidez de las imágenes fílmicas, utiliza lo cinemático como una interferencia que provoca inmovilidad. Puesto que la mayor paradoja del cine es que permite representar la continuidad y el movimiento a partir de la fragmentación y la detención, Saer saca provecho de ese conflicto que está en la base de las películas: no adopta el modelo de la representación cinematográfica dominante sino que utiliza sus técnicas de registro como estrategia de producción literaria. En este sentido, lo cinemático no remite al ejemplo estilístico de los films hegemónicos sino a los rudimentos mismos del dispositivo: el protocinema de los cronofotógrafos durante el siglo XIX.

En efecto, en los experimentos de Marey y de Muybridge ya estaba anunciado todo el cine; sin embargo, unos años antes de 1895, esa síntesis del movimiento analíticamente descompuesto que consigue el aparato de los hermanos Lumière era aún una utopía. Los experimentos cronofotográficos se mantienen en el limbo de la transición entre un modelo de representación y otro. Saben, sobre todo, qué es lo que irremediablemente ya no pueden ser, aunque todavía no entiendan con demasiada claridad hacia dónde avanzan. Hay un universo de representación que estas imágenes clausuran y, a la vez, otro que inauguran aunque apenas lo intuyen. Más que una afirmación, una sospecha. Los Films - se sabe- no son imágenes en movimiento sino imágenes del movimiento que se suceden unas a otras y que, por un efecto de la óptica (ya que el ojo sutura los espacios entre ellas), produce la ilusión de una continuidad allí donde sólo hay instantes fijos y discontinuos. El cine necesitó olvidar esa procedencia para construir una representación aceptable del tiempo y del movimiento; pero lo que Marey y Muybridge descubrieron es que sólo se puede mostrar la fluidez y el transcurrir a partir de la detención y el intervalo. Es decir, la continuidad no puede capturarse sino artificialmente: su registro implica una descomposición que la convierte en una sucesión más o menos arbitraria de poses fijas.

En su interpretación crítica de Henri Bergson, Deleuze distingue dos maneras de reconstruir el movimiento: la antigua y la moderna.

Para la antigüedad, la representación de una acción debía capturarla en su punto culminante, en su acmé: la reconstrucción del movimiento supone una sucesión ordenada de poses o instantes privilegiados que sintetizan la esencia de esa acción. "La revolución científica moderna -escribe Deleuze- consistió en referir el movimiento no ya a instantes privilegiados sino al instante cualquiera. Aun si se ha de recomponer el movimiento, ya no será a partir de elementos formales trascendentes (poses), sino a partir de elementos materiales inmanentes (cortes). En lugar de hacer una síntesis inteligible del movimiento, se efectúa un análisis sensible de éste" (Deleuze, 1984, p. 17). Según una concepción tradicional, el arte debe ofrecer una síntesis, es decir, un instante en donde el todo se revela; allí radica el sentido de la pose en tanto punto de condensación. El problema que suscitaron las cronofotografías de Marey y las instantáneas equidistantes de Muybridge era que no podían remitirse a una serie de momentos privilegiados: tomadas aisladamente, cada una de esas imágenes en que se 
descomponía un desplazamiento no actualizaba ninguna esencia, ninguna forma trascendente. Lo que permitió el surgimiento del dispositivo cinematográfico no fue otra cosa que la reconstrucción del movimiento a partir de esos momentos cualesquiera (no un corte inmóvil al que se le añadiría un movimiento abstracto, sino un corte móvil).

La negatividad - en el sentido adorniano - de ese momento cronofotográfico (o sea: pre-cinematográfico) es lo que interesa para pensar la literatura de Saer. Del movimiento como dato de la realidad a su descomposición, lo que le preocupa al escritor no es la fluidez sintética del cine sino su contradicción, su punto de tensión, su instante no reconciliado. Los textos de Saer exploran esa paradoja que se hallaba en la base de los ensayos cronofotográficos. Para él -igual que para Marey y para Muybridge- describir la percepción es sospechar de lo que se percibe y, por eso, su escritura aprovecha críticamente el efecto producido por las sucesiones de fotografías. Es decir: no intentar trasladar la fluidez del cine en tanto modo de representación, sino apropiarse del mecanismo cronofotográfico que se halla en su base para ejercer una violencia en el interior del discurso literario.

Escritor en el siglo del cine, Saer trabaja sobre las consecuencias que produce la desagregación: exaspera esa tensión compleja que circula por debajo de las acciones en apariencia más simples, ensanchándolas hasta volverlas imposibles. "La mayor" es, en este punto, un texto clave:

\begin{abstract}
Y si hubiese, es un decir, lo que pudiésemos llamar, por decir así, un sentido, o sea un corte, arbitrario, irrisorio, en la gran mancha que se mueve, ¿cómo? ¿dónde? ¿cuándo? y sobre todo: ¿por qué?, si hubiese, entre dos puntos, uno al que pudiésemos llamar el principio, otro al que le pudiésemos decir el fin 0 , respectivamente, la causa y el efecto, se podría decir que, sin haber recibido ningún llamado, sin ninguna finalidad, paso, del principio al fin, del cuarto iluminado a la terraza gélida, atravieso, como quien dice, el hueco de la puerta, y, sin que haya intervenido ningún llamado tampoco, ningún llamado, del fin al principio, del efecto, por llamarlo así, a la causa, de la terraza oscura, fría, a la habitación cuya luz, tenuemente, el humo vela, sin que nadie, pero nadie, pueda decir verdaderamente cómo, ni dónde, ni cuándo, ni, sobre todo, por qué. (Saer, 1982 , p. 25, 26)
\end{abstract}

Lo que obsesiona al narrador hasta la parodia es la búsqueda de alguna finalidad en los actos, alguna conexión que lleve de uno a otro, que revele alguna estructura subyacente a esa realidad informe en la que se mueve como hundiéndose en el lodo.

Parecería que las cosas subsisten únicamente mientras son sostenidas por la mirada que las describe. Y luego, más allá de ella, desaparecen. Así reflexiona Tomatis, en La grande, cuando la noche lo sorprende arriba de un micro en el camino de vuelta a casa:

¿Seguirá estando en su lugar la ciudad? Los lugares, cuando no los atravesamos empíricamente, ¿siguen existiendo, o por lo menos siguen existiendo de la misma manera? [...] Igual que cuando se piensa demasiado en la respiración puede volverse dificultoso respirar, cuando se toma conciencia de vivir a la vez en el espacio y en el tiempo, las cosas más simples se vuelven complicadas y extrañas: así, desde que dejó la ciudad esta mañana temprano hasta que vuelva a entrar en ella esta noche, la existencia de la ciudad, que depende únicamente de su memoria, se vuelve de lo más problemática. (Saer, 2005, p. 356). 
Así, la escritura restituye al mundo su carácter de enigma y ejerce sobre él las tareas de una auténtica interrogación. Lo que le interesa a esta literatura no es el film en tanto representación de la fluidez sino ese punto de descomposición cinética en donde toda acción se reduce a una serie de momentos inconmensurables. Capturada en su propio reverso, en su negatividad, la imagen cinematográfica exhibe un carácter no reconciliado consigo misma que puede ser provechoso para la literatura.

\section{La literatura en el cine}

¿Cómo trabajar, entonces, estos relatos desde el cine? ¿Cómo transformar las palabras en imágenes sin avenirse a una mera ilustración que elimine todas las fricciones, que suavice todos los contrastes? El cine suele buscar en la literatura argumentos que pueda ilustrar con imágenes en vez de interpelar a los textos para establecer con ellos un diálogo crítico. Un diálogo crítico, es decir: un intercambio en donde el cine funcione como un modo de leer el texto en otra lengua y en donde las imágenes no sean vehículos de una historia que es previa y exterior a ellas.

Se da por sentado que ciertos textos son más "cinematográficos" que otros. El propio Eisenstein sostiene que las novelas de Emile Zola podrían filmarse así como están, sin más trámite, porque son ya guiones acabados. ¿Pero qué se quiere decir cuando se afirma que un texto literario es más cinematográfico que otro? Más que definir la naturaleza del texto (que siempre es, en un sentido, infilmable), ese postulado revela la concepción que tiene sobre el cine aquel que lo enuncia: entendido, básicamente, como cine de acción. Es lo que François Truffaut critica a la "tradición de calidad" del cine francés: películas que se limitan a ilustrar un guión que, a su vez, no ha hecho más que domesticar un texto literario, como si se tratara de "reeducar a un delincuente buscándole trabajo" (Truffaut, 1989, p. 233).

Tal vez, en efecto, no es cuestión de buscar un acuerdo sino de profundizar las discrepancias entre ambos discursos, las discontinuidades, el malentendido. Tanto más en los relatos de Saer, donde todo hilo argumental es procesado por un estilo voraz que desmenuza hasta el extremo todas las acciones. El cine y la literatura comparten un tipo de representación basada en un encadenamiento de sucesos que, por eso mismo, favorece la emergencia de una organización narrativa. Saer es un gran narrador, sin dudas; pero aunque nunca abandona su historia, la somete permanentemente a un conjunto de torsiones poéticas que la invaden y la desfiguran bajo esa hiperinflación formal de la escritura. En todo caso: lo que se cuenta y el modo en que se cuenta resultan inseparables. Pero si el cine es utilizado en su negatividad (en tanto fragmentación y detención del movimiento), ¿cómo adaptar estos textos? ¿De qué manera puede una película servirse de ellos siguiendo ese mismo sentido negativo o no reconciliado? Es decir: ¿en qué medida la literatura puede dejar de ser una mera proveedora de relatos para constituirse en un material perturbador a partir del cual los films no busquen convalidarse sino ponerse en cuestión? 
La literatura de Saer no ha tenido demasiada fortuna con sus adaptaciones cinematográficas. ${ }^{5}$ Sin embargo, Nicolás Sarquís logra captar el tono cansino y seco de "Palo y hueso" así como Raúl Beceyro se formula con precisión algunas preguntas básicas sobre la relación entre cine y literatura en su versión de Nadie nada nunca: ¿qué significa adaptar un texto?, ¿qué se traslada de un discurso al otro? y, sobre todo, ¿cómo se representa ese universo de la literatura de Saer por medios cinematográficos? La literatura -suele decirse- tiende a la expansión mientras que el cine trabaja sobre la intensidad y la síntesis. Curiosamente, Beceyro elige ir en contra de ese extendido dictum audiovisual: no reduce ni comprime sino que recorta una zona de la novela y luego discurre largamente sobre ella. Véase, por ejemplo, la larga escena inicial en la que el personaje prepara mate y corta salame: el cineasta no acelera sino que se detiene sobre ciertos instantes y se demora en ellos. Como si hubiera descubierto allí una forma que no ilustra un argumento sino que profundiza, por medios cinematográficos, un tono que ya estaba en el texto.

Retrato de Juan José Saer, el documental de Rafael Filippelli, no trabaja sobre un texto del escritor sino con el escritor en tanto productor de textos. De manera significativa, esta película que pretende dar cuenta de un autor de excepción insiste en mostrar a su protagonista en situaciones familiares y cotidianas. Pero en esa acumulación de momentos aparentemente insignificantes, Filippelli construye puntos de condensación discreta: unas pocas miradas de leve intensidad, como débiles epifanías, que apenas se elevan por encima del conjunto y enseguida se diluyen. El film no pretende definir o caracterizar esa percepción sino, simplemente, acusar su presencia: a veces por el hecho de mantener la cámara sobre el escritor mientras sigue una conversación fuera de cuadro, a veces acompañando su imagen atenta y eliminando todo sonido de referencia, a veces espiándolo cuando observa un paisaje. El cine no puede nombrar ese momento inefable de la creación, pero puede insinuarlo de manera oblicua.

El propio escritor reconoce allí, en el documental, que no se trata sólo de aprovechar un material sino de procesarlo. Frente a la cámara, enuncia el verdadero desafío del cine ante la literatura y ante los literatos:

\begin{abstract}
El conflicto principal de este tipo de films sobre un escritor o un artista es que se espera que diga cosas importantes sobre su arte. Pero al mismo tiempo es un retrato $y$, entonces, esa persona aparece en su vida cotidiana, que es igual a la de todo el mundo. Entonces me pregunto, pero no sólo sobre este film sino sobre todos los films documentales: ¿dónde y por qué medios es posible crear un sistema expresivo propio frente a ese peso de lo cotidiano y lo banal, que es la materia con la que trabaja?
\end{abstract}

El comentario resulta particularmente significativo en boca de un autor que ha construido su literatura sobre los movimientos de un muchacho que renguea, por ejemplo, o a partir de la conversación entre dos conocidos que se encuentran y

\footnotetext{
${ }^{5}$ Varios textos de Saer fueron llevados al cine: Palo y hueso (Nicolás Sarquís, 1967), Nadie nada nunca (Raúl Beceyro, 1988), Cicatrices (Patricio Coll, 2001), Tres de corazones (Sergio Renán, 2007, sobre el relato "El taximetrista").
} 
caminan juntos por unas cuadras. O sea: un escritor cuyos textos no buscan su densidad estética en el carácter excepcional de los episodios narrados sino en el modo de tratarlos literariamente.

Si ese escritor dice lo que dice en un film que se propone retratarlo, no habría que entender su comentario como una reticencia o una interdicción o un impedimento sino, en todo caso, como una invitación y un desafío: ¿será capaz el cine de tratar a la literatura del mismo modo en que la literatura trata lo real?, ¿podrá la película considerar el texto como algo tan significativo o tan poco significativo como lo es la materia con que trabaja ese texto? y, por último, ¿se atreverá el cineasta a confiar en su propia intervención crítica para construir un discurso audiovisual en vez de descansar sobre los logros de la escritura? Lo cierto es que el film parecería desoír la advertencia de su protagonista y elige mostrarlo en aquellas actividades que no lo distinguen de las demás personas: viaja, compra vinos, participa de almuerzos de despedida y de bienvenida, visita a amigos, pasea por Buenos Aires o Santa Fe, se ocupa de la promoción de sus libros. Siempre rodeado de gente, el retrato del escritor prescinde justamente del momento íntimo de la escritura y de la creación.

Desde el principio, la voz en off de Filippelli leyendo textos del propio Saer se encarga de desvirtuar, en el viaje del escritor, cualquier expectativa reveladora sobre su poética:

el mito de reencontrar los afectos y los lugares de mi infancia y de mi juventud me incitó a efectuar estos viajes repetidos que se han transformado, después de más de una década, en una costumbre, lo bastante monótona como para generar, desde el punto de vista del placer, una ambivalencia notoria [...] Así, entre el almuerzo de despedida en París que se prolonga hasta bien entrada la tarde, y el asado de bienvenida en Buenos Aires al día siguiente, despegues, aterrizajes y escalas, siempre los mismos, producen en mí las mismas sensaciones, los mismos estados de ánimo, las mismas asociaciones e incluso los mismos pensamientos, que más de una vez me han parecido novedosos hasta comprobar que ya los había consignado en mi libreta de apuntes en algún viaje anterior.

En esos momentos en que la cámara evidencia su más absoluta superficialidad se intuye una profundidad misteriosa e inexplicable.

La estructura del viaje, que habilita para el escritor el punto de vista un poco exterior del que regresa, es la clave en donde se cifra esa mirada singular. En todo caso, Saer necesita construir ese lugar del origen como una lejanía o una ausencia. Como si se dijera: sólo en el gesto de sustraerse a la cotidianeidad (cuya modulación extrema sería el exilio) es posible escribir. Y a la vez: ¿cómo podría escribirse algo que no estuviera esencialmente ligado a esa cotidianeidad? La pérdida es, entonces, casi una donación, un gesto sacrificial del artista, un momento de su ascesis. Habría que preguntarse no sólo qué vuelve a buscar Saer en cada viaje, sino también qué trae consigo, cuál es ese contrabando involuntario inoculado en su mirada como si fuera un virus. Es posible ser fiel a una región; sólo que, para eso, es preciso traicionarla, abandonarla, partir. Perderla. En esa memoria precisa y a la vez anacrónica del exiliado, los bordes difusos de la geografía adquieren su nitidez literaria. 
Escribir (filmar) es siempre un desarraigo. Sólo se puede escribir sobre aquello que se convierte en una obsesión porque se ha extraviado definitivamente. Por lo tanto, no se vuelve para recuperar lo perdido sino para conquistar el valor irremediable de la ausencia. Lo perdido es eso que se transforma en una falta recurrente y necesaria. Si hay algo desgarrador en el viaje es porque en esa recuperación imposible se revela un vínculo más profundo e inalienable que cualquier posesión. El film de Filippelli concluye con una larga panorámica del paisaje litoraleño (fantasmal subjetiva del escritor reconociendo su región) mientras su voz en off reproduce la de Saer:

\begin{abstract}
El placer melancólico, no exento ni de euforia, ni de cólera ni de amargura, que me daba su contemplación, era un estado específico, una correspondencia entre lo interno y lo exterior, que ningún lugar del mundo podría darme. Como a toda relación tempestuosa, la ambivalencia la evocaba en claroscuro, alternando comedia y tragedia. Signo, modo o cicatriz, lo arrastro y lo arrastraré conmigo dondequiera que vaya. Más todavía: aunque trate de sacudírmelo como una carga demasiado pesada, en un desplante espectacular, 0 poco a poco $y$ subrepticiamente, en cualquier esquina del mundo, incluso en la más imprevisible, me estará esperando.
\end{abstract}

La célebre zona saeriana, entonces, es un sitio transportable. Una fijación sí, pero no un punto fijo. Es un destino pacientemente forjado en la memoria. "El fin del arte no es representar lo Otro sino lo Mismo", escribe Saer en El río sin orillas (Saer, 1991, p. 218). También podría haber escrito: el fin del arte es representar lo Mismo como lo Otro. Distanciarse de una obsesión no es negarla sino, en cierta forma, hacerla siempre presente.

En la acumulación de pequeños presentes aislados, Saer construye una poética que escenifica la experiencia de una percepción desoladoramente fragmentaria, es cierto; pero también, retrotrae las cosas hasta un punto en donde el conocimiento ya no se halla colonizado por la costumbre sino aguijoneado por el afán exploratorio. Deteniendo y fragmentando el flujo del acontecer, sus textos se concentran en una particular fenomenología del movimiento y del tiempo. Pero más que avanzar hasta un punto máximo de descomposición en donde las cosas supuestamente entregarían su esencia, el poder de esta escritura consiste en encontrar el pasadizo entre cada fragmento insignificante y la totalidad inabarcable. Entonces, finalmente, la literatura es investida de una función crítica porque se vuelve incontrolable y, a lo largo de una obra perfecta, hace que cada instante se proyecte sobre la perspectiva majestuosa de una cosmogonía.

\title{
Bibliografía
}

BECEYRO, Raúl. "Sobre Saer y el cine". Punto de vista 43, Buenos Aires, 1992.

COMPANY, Juan Miguel. El trazo de la letra en la imagen. Texto literario y texto fílmico. Madrid: Cátedra, 1987.

DELEUZE, Gilles. La imagen-movimiento. Estudios sobre cine 1. Barcelona: Paidós, 1984. 
MONTALDO, Graciela. Juan José Saer: El limonero real. Buenos Aires: Hachette, 1986.

OUBIÑA, David y Alejandro Ricagno, "Glosa a la hora de la siesta. Entrevista con Juan José Saer". El Amante 34 (1994).

PIGLIA, Ricardo. Crítica y ficción. Buenos Aires: Siglo XX, 1990.

ROBBE-GRILLET, Alain. "Tiempo y descripción en el relato de hoy", en Por una novela nueva. Barcelona: Seix Barral, 1964.

SAAVEDRA, Guillermo. "Juan José Saer: El arte de narrar la incertidumbre", en La curiosidad impertinente. Entrevistas con narradores argentinos. Rosario: Beatriz Viterbo, 1993.

SAER, Juan José. "La mayor". en La mayor. Buenos Aires: Centro editor de América Latina, 1982.

. El río sin orillas. Buenos Aires: Alianza, 1991.

. La grande. Buenos Aires: Seix Barral, 2005.

SARLO, Beatriz. "Narrar la percepción". Punto de vista 10, Buenos Aires,1980.

TRUFFAUT, François. "Una cierta tradición del cine francés", en Joaquim Romaguera i Ramió y Homero Alsina Thevenet (eds.), Textos y manifiestos del cine. Madrid: Cátedra, 1989.

\begin{abstract}
What is the relationship between modern literature and cinema? What kind of films do writers have in mind? What does writing take from images? Strongly influenced by narrative innovations of modern literature, the work of Juan José Saer hasn't escaped to the magnetic appeal of cinema. But although he uses cinematographic techniques to break up with classical narration in literature, he never adopts the model of dominant cinema. On the contrary, he takes advantage of the idea of fragmentation and stop motion (that constitute the basis of films) to give birth to a new form of literature. But if Saer uses cinema in its negative form, then how to produce film adaptations from his literary work? How is it possible to transform words into images without falling in a mere illustration that would eliminate every tension and would neutralize every contrast? This essay connects literature and cinema in order to reflect on the ways Saer's writing has used film devices and the ways in which films have adapted their novels.
\end{abstract}

\title{
Keywords
}

Modern literature. Film adaptation. Cinematographic devices. Chronophotography. Stop motion and fragmentation of movement. 